\title{
EVALUACIÓN DE PRÁCTICAS ASOCIADAS CON LA REMOCIÓN DE FLORES, FRUTOS LATERALES O CENTRALES Y/O DE LA PRIMER MANO BASAL EN EL RACIMO DE BANANO
}

\author{
Alfonso Vargas*
}

Palabras clave: Desflora, desmane, manejo precosecha, Musa AAA, remoción de frutos.

Keywords: Deflowering, dehanding, fruits removal, Musa, AAA, pre-harvest management.

Recibido: 12/11/12

Aceptado: 03/03/13

\begin{abstract}
RESUMEN
Prácticas relacionadas con el manejo del racimo de banano, se evaluaron en el Caribe costarricense durante el 2011 por medio de 6 experimentos. Estos fueron, 1 y 2: con (testigo) y sin desflora; 3 y 4: $\sin$ (testigo) y con desgaje; 5 y 6: a-remoción de 3 manos inferiores y/o remoción de frutos centrales de la primera mano (túnel), bremoción de la primera mano y 2 manos inferiores, y c- remoción de 2 manos inferiores, confección de un gajo (mano inferior) y túnel (primera mano). Se evaluaron variables de producción y aprovechamiento. En los experimentos de desflora y desgaje, salvo excepciones, no hubo diferencias ( $p>0,0620)$ para las variables de producción entre ejecutar o no la labor. En los experimentos 5 y 6 no hubo diferencias $(p>0,0804)$ salvo en el peso del racimo $(p<0,0450)$, grosor $(p>0,0109$; en la primera y cuarta mano, experimento 5) y longitud ( $\mathrm{p}=0,0443$; segunda mano, experimento $5)$ del fruto. Las causas de rechazo no difirieron entre tratamientos $(p>0,0652)$ excepto para cicatriz de crecimiento $(\mathrm{p}=0,0353$; experimento 2$) \mathrm{y}$ lesión nueva ( $\mathrm{p}=0,0192$; experimento 6). El rendimiento exportable fue similar ( $>00,5750)$ entre desflorar o no. En el experimento 3 los racimos con gajo tuvieron mayor rendimiento exportable $(\mathrm{p}<0,0045)$ y aprovechamiento $(\mathrm{p}<0,0007)$ en primera calidad. En los experimentos 5 y 6 no
\end{abstract}

\begin{abstract}
Evaluation of practices associated with the removal of flowers, lateral or central fruits and/or first hand in the banana bunch. Practices associated with banana bunch management were evaluated in the Caribbean of Costa Rica during 2011 in 6 experiments. These were, 1 and 2: with (control) and without deflowering; 3 and 4: without (control) and with central fruit cluster in lower hand; 5 and 6: a-removal of 3 lower hands and / or tunnel (first hand), b-removal of the first hand and 2 lower hands, and c-removal of 2 lower hands, conformation of fruit cluster (lower hand) and tunnel (first hand). Production and performance variables were measured. Experiments testing deflowering and fruit cluster showed no differences $(p>0.0620)$ in production variables between treatments. Neither in experiments 5 and 6, except for bunch weight $(p<0.0450)$, fruit thickness $(p>0.0109$, first and fourth hand, experiment 5) and fruit length ( $\mathrm{p}=0.0443$; second hand, experiment 5); no differences $(p>0.0804)$ were found in the remainder variables. Rejection components did not differ between treatments $(\mathrm{p}<0.0652)$ except for growth scar $(\mathrm{p}=0.0353$; experiment 2$)$ and fresh injury ( $\mathrm{p}=0.0192$; experiment 6$)$. Exportable performance was similar $(p>0.5750)$ between deflowering treatments. In experiment 3 bunches
\end{abstract}


hubo diferencias $(p>0,0612)$ entre tratamientos. A pesar de que en muchos casos las diferencias en aprovechamiento no alcanzaron significancia estadística, estas representaron un aumento importante en aquellos racimos con gajo.

\section{INTRODUCCIÓN}

En el manejo precosecha del racimo de banano las prácticas en las que se remueven algunas de sus partes como flores, frutos o manos completas, generan habitualmente, en su uso, diferentes criterios, que pueden ser desde contradictorios hasta controversiales entre sí. Además, la información científica es poco disponible y fragmentada por lo que es necesario definir con mayor precisión los alcances reales de dichas prácticas. Al respecto, Vargas y Blanco (2000) demostraron que la variación en los resultados de diferentes experimentos relacionados con estos temas, es fundamentalmente debida al uso de metodologías de evaluación y análisis inadecuadas. Dichos autores sugieren una metodología de evaluación basada en el uso de racimos con igual número de manos verdaderas (racimos equivalentes) y la comparación de manos con igual posición en el racimo (manos equivalentes) como comparadores de tratamiento. Bajo este concepto se han realizado estudios de remoción de flores o desflora (Vargas et ál. 2003), de frutos laterales (desdede) individuales (Vargas 2003), de grupos laterales de frutos (apicales) o desgaje (Vargas 2007,2008 ) o de la primera mano basal o desmane superior (Vargas 2006).

La desflora consiste en eliminar manualmente el periantio, los estambres y el estilo terminal que persisten adheridos al fruto. En banano esta labor se realiza durante los primeros 15 días, después de haber emergido el racimo por el boquete floral. En esta etapa la remoción de los rudimentos foliares es más fácil y los with fruit cluster showed higher export yield $(p<0.0045)$ first quality performance $(p<0.0007)$. In experiments 5 and 6 no differences $(\mathrm{p}<0.0612)$ were detected between treatments. Although in many cases the differences did not reach statistical significance on exportable fruit, these represent an important increase in those bunches with fruit cluster.

exudados no manchan el fruto (Daudin 1953, Sandoval y Pérez 1998). También algunas fincas no desfloran en el campo sino que realizan esta práctica cuando los racimos ingresan a la planta empacadora. Diversos autores recomiendan la desflora en el campo para disminuir la incidencia de lesiones en el racimo debidas al crecimiento de los frutos (Robinson 1996, Soto et ál. 1992), de enfermedades (Champion 1975, Robinson 1996) y de daños causados por (Pyroderces rileyi ) o "gusano basurero" (Rodríguez 1996, Sandoval et ál. 2000, Coto y Saunders 2004). Además, Sandoval y Pérez (1998) y Sandoval et ál. (2000) indican que los frutos con desflora en el campo presentan un mayor peso promedio del racimo y mayor calibración que aquellos no desflorados.

La mayoría de estos experimentos consideraron el uso de fundas protectoras impregnadas con clorpirifos para la protección del racimo, el único insecticida disponible en ese momento para dicho fin. Sin embargo, según Uquillas (2002) y Cubillo et ál. (2003), este insecticida no es efectivo para el combate de $P$. rileyi. Por lo tanto, la desflora en el campo constituiría una práctica importante de manejo para prevenir el daño causado por este insecto, especialmente en épocas secas. No obstante, el desarrollo reciente de fundas impregnadas con el insecticida bifentrina se ha constituido en una alternativa eficiente de combate de $P$. rileyi (Cubillo et ál. 2003, Cubillo 2004) y se podría eliminar la desflora en el campo con la consiguiente reducción de costos. Esto cobra mayor relevancia toda vez que Vargas et ál. (2003) y Rivas et ál. (2009) demostraron que los racimos cuyos frutos fueron desflorados en 
el campo y embolsados con fundas impregnadas con clorpirifos no presentaron un mejoramiento en las dimensiones, en la apariencia ni en cantidad de cajas obtenidas por racimo con respecto a aquellos sin desflora y embolsados con fundas impregnadas con bifentrina. Adicionalmente, ambos autores coinciden en señalar una reducción de la cicatriz de crecimiento y látex cuando las partes florales permanecieron adheridas al fruto hasta la cosecha. Esto indica que bajo las opciones tecnológicas disponibles para el manejo precosecha del racimo la desflora en el campo no representaría un beneficio para el productor.

Por otra parte, la remoción de grupos laterales de frutos de manos apicales o desgaje (Figura 1) es una práctica de reciente difusión

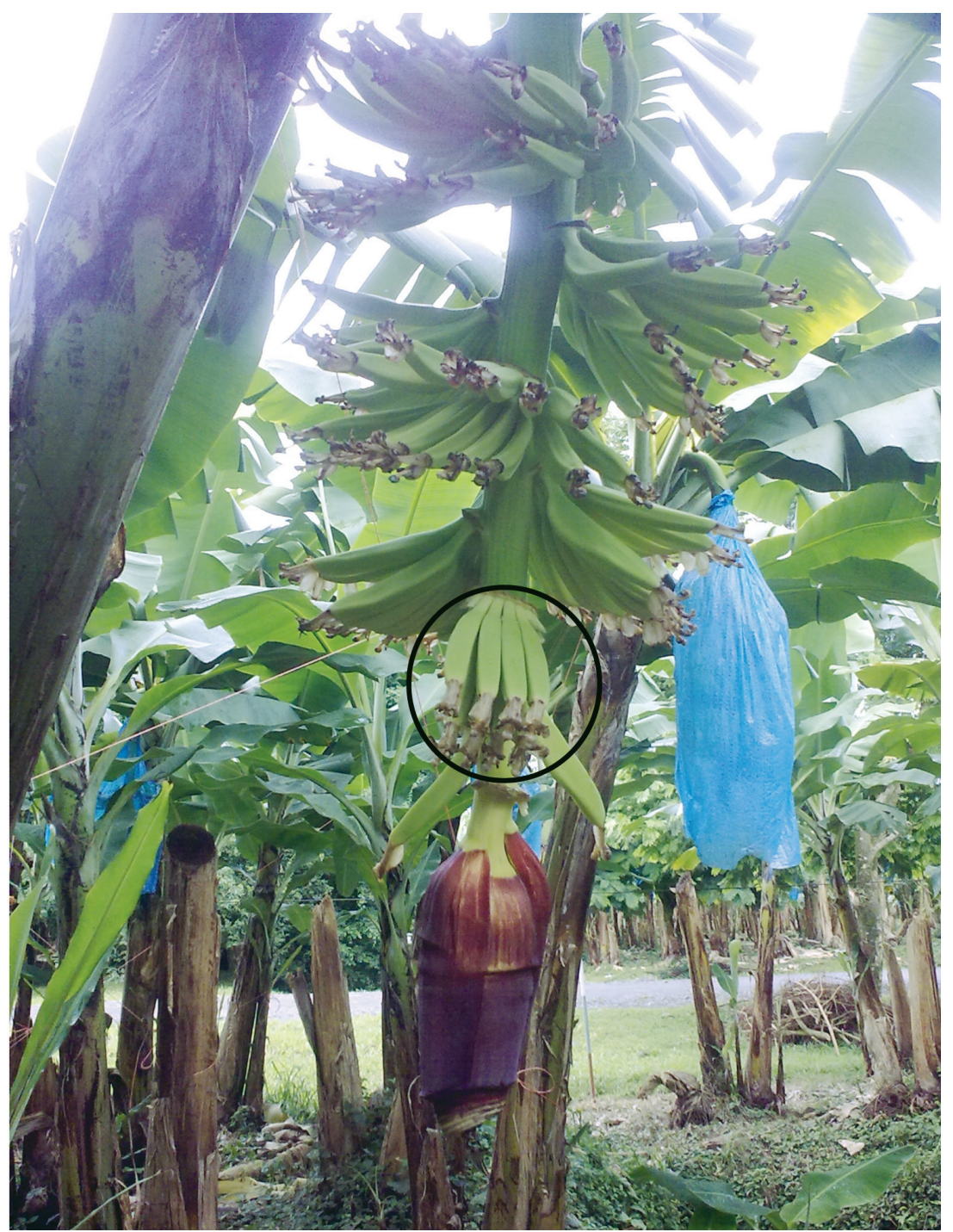

Fig. 1. Se destaca racimo de banano (Musa AAB) con un gajo conformado a partir de la última mano de posición inferior a descartar por el desmane. La intensidad de desmane está indicada en la figura por la retención de un fruto en cada una de las manos removidas, en este caso de 2. La tercera de posición superior a éstas, que de acuerdo con la instrucción de la labor debía también ser removida, ya que se conformó el gajo. 
y consiste en la eliminación de grupos de frutos laterales a cada lado de la mano en una o más de ellas normalmente descartadas por el desmane para la conformación de un gajo central de 6 a 8 frutos. Experimentos realizados por Vargas (2007) indican que esta labor, realizada en la mano de mayor posición en el racimo que sería desmanada permite que el gajo resultante se pueda aprovechar, de acuerdo con las normas de calidad, sin detrimento de las dimensiones de los frutos remanentes, ni del intervalo de tiempo entre el desmane y la cosecha. No obstante, en virtud de lo anterior, el impacto más importante de la práctica está constituido por la posibilidad de definir sin riesgo, de forma práctica y rápida las intensidades de desmane más apropiadas de acuerdo con las condiciones agronómicas y de comercialización de una plantación.

Dentro de las modalidades de desmane, en ocasiones se utiliza una de manos superiores que comprende la eliminación total de la primera mano y la compensación o reposición de ésta en el desmane, por otra de posición inferior en el racimo. De acuerdo con Calvo (1984) esta labor reduce el índice de curvatura y conforma frutos más rectos en las restantes manos y podría tener un efecto favorable en la calidad del fruto de exportación. No obstante, Vargas (2006) determinó una reducción en el peso del racimo cuando se eliminó la primera mano y se sustituyó por otra de posición inferior en el desmane. Asimismo dicho autor no encontró diferencias en las dimensiones y en el índice de curvatura del fruto, ni en la conformación de manos remanentes de igual posición entre racimos con y sin remoción de la primera mano y al igual que Calvo (1984) también determinó una pérdida del aprovechamiento. Vargas (2006) indica que la remoción total de frutos de la primera mano solo redujo la cantidad de frutos deformes por racimo en la época adversa, condición que sin embargo, no fue suficiente para mejorar la relación de cajas por racimo (ratio) con respecto al tratamiento en donde no se removieron manos verdaderas apicales. Dado que las manos superiores constituyen la porción más importante del racimo para el empaque, la remoción total de la primera mano probablemente solo se puede justificar en aquellos casos en que ésta se presente con mucho menos frutos de lo normal (14 frutos o menos), fenómeno que se conoce en el léxico bananero como "mano mica". Al respecto, una medida de mitigación con el propósito de reducir el desacomodo natural del exceso de frutos que por épocas presentan las manos superiores y principalmente la primera de ellas está dada por la remoción de un grupo de frutos centrales que incluya tanto la primera como la segunda fila de la mano, denominado como túnel (Figura 2) y cuyos racimos presentaron mayor peso de racimo en comparación sus similares donde se eliminó la primera mano (Vargas 2006).

El objetivo del presente estudio consistió en evaluar el comportamiento de racimos con y sin remoción de flores en el campo (desflora), sin y con la conformación de un gajo en la mano de mayor posición en el racimo que sería desmanada (desgaje), con la eliminación total de la primera mano (desmane superior) y con la remoción de un grupo de frutos centrales en la primera mano (túnel). 


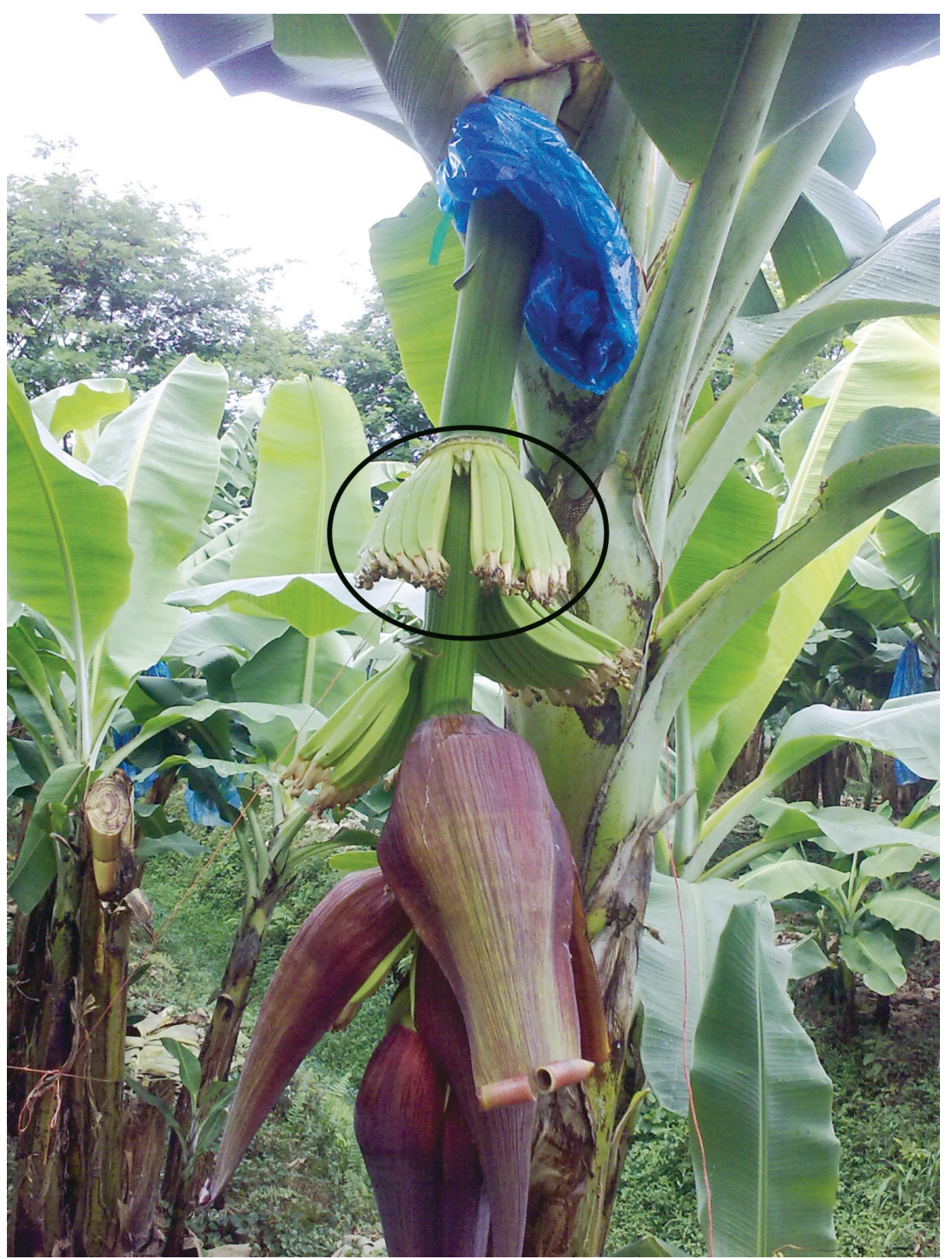

Fig. 2. Se destaca racimo de banano (Musa AAA) con la remoción de un grupo de frutos centrales en su primera mano conocido como 'túnel'.

\section{MATERIALES Y MÉTODOS}

Seis experimentos se realizaron durante el 2011 en 2 fincas comerciales de banano (Musa AAA) ubicadas en el Caribe de Costa Rica.

En la finca Probana establecida en 1986 y ubicada en el cantón de Matina en la zona este del río Reventazón se realizaron los experimentos del
1 al 4. El área experimental fue 7,34 ha, estuvo conformada por el cv. Grande Naine en una densidad de población de 1600 plantas.ha $^{-1}$. Registros climáticos de una estación meteorológica cercana, indican que durante el 2011 la precipitación acumulada fue de $2959 \mathrm{~mm}$, la temperatura máxima y mínima promedio de 31,0 y $22,3^{\circ} \mathrm{C}$, 
respectivamente y la humedad relativa promedio de $79,8 \%$. El suelo es de origen sedimentario y su nombre textural es franco arcilloso con $22,0 \%$ de arena, $28,0 \%$ de arcilla y $51,0 \%$ de limo y las siguientes características: $\mathrm{pH} 6,55$; materia orgánica 1,28\% y un contenido de bases de: Ca 21,9; K 0,32; Mg 6,98 $\mathrm{cmol}^{-1}$. La fertilización anual se realizó mediante la adición de $400 \mathrm{~kg}$ de N, 24 $\mathrm{kg}$ de $\mathrm{P}_{2} \mathrm{O}_{5}, 403 \mathrm{~kg}$ de $\mathrm{K}_{2} \mathrm{O}, 90 \mathrm{~kg}$ de $\mathrm{MgO}, 91 \mathrm{~kg}$ de $\mathrm{CaO}, 66 \mathrm{~kg}$ de $\mathrm{S}, 1,8 \mathrm{~kg}$ de $\mathrm{Zn}$ y 3,3 kg.ha-1. $\mathrm{año}^{-1}$ de B, fraccionada en 24 ciclos.

En la finca Encantos del Mar Rojo establecida en 1993 y ubicada en el cantón de Sarapiquí en la zona oeste del río Reventazón, se realizaron los experimentos 5 y 6 . El área experimental fue de 9,81 ha estuvo conformada por el cv. Grande Naine en una densidad de población de 1600 plantas.ha ${ }^{-1}$. Registros climáticos de una estación meteorológica cercana indican que para el 2011 la precipitación acumulada fue de $3898 \mathrm{~mm}$, la temperatura máxima y mínima promedio de 32,4 y $20,2^{\circ} \mathrm{C}$, respectivamente y la humedad relativa promedio de $82,7 \%$. El suelo es de origen volcánico y su nombre textural es Franco Arenoso con $55,1 \%$ arena, $7,5 \%$ arcilla y $37,5 \%$ limo y las siguientes características: $\mathrm{pH} 4,8$; materia orgánica $5,0 \%$ y un contenido de bases de: $\mathrm{Ca} 3,9 ; \mathrm{K}$ 0,1; $\mathrm{Mg}$ 1,1 cmol. $\mathrm{l}^{-1}$. La fertilización se realizó mediante la adición de $377 \mathrm{~kg}$ de $\mathrm{N}, 45 \mathrm{~kg}$ de $\mathrm{P}_{2} \mathrm{O}_{5}, 603 \mathrm{~kg}$ de $\mathrm{K}_{2} \mathrm{O}, 90 \mathrm{~kg}$ de $\mathrm{MgO}, 111 \mathrm{~kg}$ de $\mathrm{CaO}, 58 \mathrm{~kg}$ de S, $2 \mathrm{~kg}$ de Zn y 2,3 kg.ha- ${ }^{-1}$.año ${ }^{-1}$ de $\mathrm{B}$ fraccionada en 13 ciclos.

El combate de la Sigatoka negra (Mycosphaerella fijiensis) en ambas fincas, se realizó mediante la aspersión aérea de fungicidas sistémicos y protectores. Los mismos se aplicaron en emulsión con aceite mineral en una proporción de 5-10 1.ha ${ }^{-1}$, de acuerdo con los requerimientos y estrategias de combate propias de cada finca y época climática. Deshojas sanitarias semanales se utilizaron como complemento al combate químico.

El desdede lateral de frutos se efectuó en los experimentos 5 y 6 con 2 manos superiores y en el experimento 4 con 3 manos superiores. Se consideró la desflora, en el transcurso de los primeros 15 días después de emitida la inflorescencia mediante 2 o 3 visitas; en la primera de ellas se llevó a cabo también el desdede de frutos laterales, esto es, manos superiores así como eliminación en la primera mano de fruto o frutos centrales en cada fila de la primera mano y de aquel o aquellos fusionados. El embolse se realizó una semana después de la floración tipo prematuro en los experimentos 1 y 2 y una semana y media después de la floración tipo semi prematuro, en los experimentos del 3 al 6. En los experimentos de desflora los racimos con testigo y sin dicha práctica se embolsaron con fundas impregnadas con clorpirifos y bifentrina, respectivamente. En ambos casos, 4 semanas después del embolse, se anudó en la parte apical del raquis una cinta de polietileno o 'corbata' impregnada con clorpirifos.

El desmane en todos los casos se realizó 2 semanas después de la floración, acompañado por la eliminación de la mano falsa y generalmente por el deschire. Cuando se consideró como parte de los tratamientos la eliminación de grupos de frutos laterales (desgaje), se realizó en conjunto con las labores anteriores. En todos los casos se respetaron las instrucciones generales de manejo precosecha del racimo de cada finca, excepto cuando alguna de dichas labores se evaluó como parte del proceso experimental. La desflora consistió en la eliminación manual del periantio, los estambres y el estilo terminal que persisten adheridos al fruto de banano. El desmane de manos inferiores consideró la eliminación completa manos verdaderas en conjunto con la mano falsa. Como mano verdadera se consideró aquel grupo de flores cuyos gineceos se desarrollaron normalmente. Como mano falsa se determinó al conjunto de flores en donde una o más de ellas se desarrollaron anormalmente, presentádose como una reminiscencia del ovario. El desgaje consistió en la conformación, mediante la remoción de frutos en ambos lados de la mano de mayor posición que normalmente se elimina en el desmane, de un gajo central de 6 a 8 frutos.

El desarrollo de los racimos transcurrió durante el 2011 de julio a octubre (experimento 1), de agosto a noviembre (experimentos 2 y 3), de setiembre a noviembre (experimento 4), 
de enero a abril (experimento 5) y de abril a julio (experimento 6). En consecuencia el experimento 1 se desarrolló en la época climática favorable, el experimento 5 en la época climática adversa y los experimentos 2, 3, 4 y 6 en el transcurso de ambas.

La cosecha de los racimos consideró 3 etapas sucesivas en los experimentos del 1 al 4, con la escogencia de la intermedia para las evaluaciones de campo y de planta empacadora con una edad después del embolse de 10 semanas en los experimentos 1 y 3 y de 11 semanas en los experimentos 2 y 4 . Adicionalmente, en esta etapa intermedia solo se cosecharon y evaluaron aquellos racimos que tenían un grosor preestablecido 44 treintaidosavos de pulgada en el fruto central de la fila externa en la segunda mano. En los experimentos 5 y 6 la cosecha de los racimos se efectuó en una sola etapa, y se consideró solamente la edad del racimo de 12 semanas después del embolse.

Las dimensiones mínimas del fruto para empaque fueron de 39 treintaidosavos en grosor y $21,0 \mathrm{~cm}$ de largo (pulpa a punta) en los experimentos del 1 al 4 y de 39 treintaidosavos de pulgada en grosor y de 20,3 $\mathrm{cm}$ de largo (pulpa a punta) en los experimentos 5 y 6 . Una calidad adicional denominada mini o junior también se consideró en ambos casos con dimensiones máxima de 37 treintaidosavos en grosor y entre 17,8 a $20,8 \mathrm{~cm}$ de largo (pulpa a punta). Esta calidad se consideró y se remuneró como primera calidad.

Los tratamientos aplicados por experimento a cada tamaño de racimo fueron los siguientes:

Experimentos 1 y 2: racimos de 9, 10 y 11 manos verdaderas a la floración, respectivamente

Tratamientos: 1- con desflora (testigo de la finca) y 2- sin desflora.

Experimentos 3 y 4: racimos de 9, 10 y 11 manos verdaderas a la floración, respectivamente

Tratamientos: 1- sin desgaje (testigo de la finca) y 2- con desgaje.

\section{Experimento 5: racimos de 10 manos verdaderas a la floración}

Tratamientos: 1- remoción de 3 manos verdaderas inferiores (testigo), 2- remoción de 3 manos verdaderas inferiores y eliminación de 2 frutos centrales en cada fila de la primera mano superior (túnel), 3- eliminación de la primera mano superior en racimos con más de 14 frutos (menos de 14 frutos no se incluyó como racimo de tratamiento) y compensación en la intensidad de desmane mediante la remoción de 2 manos verdaderas inferiores y 4- eliminación de 2 frutos centrales en cada fila de la primera mano superior (túnel), eliminación de grupos de frutos laterales con la retención de un gajo central de entre 6 a 8 frutos en la mano inferior de mayor posición a descartar por el desmane y remoción de 2 manos verdaderas inferiores.

\section{Experimento 6: racimos de 10 manos verdaderas a la floración}

Tratamientos: 1- Remoción de 3 manos verdaderas inferiores (testigo), 2- eliminación de la primera mano superior en racimos de más de 14 frutos (menos de 14 frutos no se incluyó como racimo de tratamiento) y compensación en la intensidad de desmane mediante la remoción de 2 manos verdaderas inferiores y 3- eliminación de 3 frutos centrales en cada fila de la primera mano superior (túnel), eliminación de grupos de frutos laterales con la retención de un gajo central de 6 a 8 frutos en la mano inferior de mayor posición a descartar por el desmane y remoción de 2 manos inferiores verdaderas.

En todos los experimentos los tratamientos se asignaron aleatoriamente, de acuerdo con la aparición de los tamaños de racimo correspondientes en la plantación. Cada planta y su racimo se consideraron como una repetición.

Las variables medidas para cada tamaño de racimo fueron: peso del racimo $(\mathrm{kg})$, grosor (treintaidosavos de pulgada) y longitud ( $\mathrm{cm}$ de pulpa a punta) del fruto central de la fila externa de manos seleccionadas. Bajo esta perspectiva se midió en los experimentos 1 y 2 el grosor 
y la longitud del fruto de las manos segunda y última y en los experimentos 3 y 4 el grosor y la longitud del fruto de las manos segunda, última comparable y última remanente (gajo) así como en los experimentos 5 y 6 el grosor y longitud del fruto de las manos primera, segunda, cuarta, sexta y octava. En los experimentos 3 y 4 (desgaje) también se midió la cantidad de racimos que durante la cosecha de los experimentos de desgaje no alcanzaron el grosor requerido de cosecha y debieron ser cosechados en etapas o semanas posteriores. El número de ellos se expresó como porcentaje del total marcado del encinte correspondiente. Adicionalmente se determinó en cada uno de los experimentos durante el proceso de empaque en la planta procesadora las causas de rechazo y la relación cajas: racimo (ratio) para cada una de las calidades obtenidas. En el experimento 3 el proceso para la obtención de estas 2 últimas variables se consideraron 2 grupos de racimos con una semana de diferencia en la cosecha y se denominaron como a y b.

El peso del racimo se midió con la ayuda de una romana Ballar ${ }^{\circledR}$ con capacidad para 50 $\mathrm{kg} \pm 200 \mathrm{~g}$. El grosor del fruto central (fila externa de la mano) se midió en la parte media del mismo, perpendicularmente al plano de la curvatura, con la ayuda de un calibrador graduado en treintaidosavos de pulgada ( 1 unidad o grado=0,794 mm). La longitud del fruto central (fila externa de la mano) se midió a lo largo de la parte externa, desde la zona de unión del pedúnculo con la pulpa, hasta el ápice (de "pulpa a punta”) con una cinta métrica de plástico graduada en $\mathrm{cm}$.
El análisis estadístico de los experimentos 1 al 4 se efectuó por separado para cada cultivar y tamaño de racimo según la estructura factorial de tratamientos $\mathrm{x}$ tamaño (número de manos) de racimo y los tratamientos se compararon entre sí mediante la prueba DMS. En los experimentos 5 y 6 los datos se analizaron mediante un análisis de varianza. Para tal efecto se utilizó el programa estadístico SAS (SAS Institute, SAS/STAT 1989).

\section{RESULTADOS}

\section{Experimentos 1 y 2: desflora}

No hubo diferencias $(\mathrm{p}>0,0900)$ en ninguna de las variables evaluadas entre racimos con y sin desflora (Cuadro 1), excepto por el mayor peso en racimos de 11 manos con desflora del experimento $2(2,4 \mathrm{~kg}$ más; $\mathrm{p}=0,0170)$ y por la mayor longitud del fruto de la última mano en racimos de 10 manos con desflora del experimento $1(0,8 \mathrm{~cm}$ más; $\mathrm{p}=0,0266)$.

Las causas de rechazo así como la merma provenientes del proceso de la planta empacadora, excepto por el mayor porcentaje de cicatriz de crecimiento de los racimos con desflora del experimento 2 (17,5\% más; $\mathrm{p}=0,0353)$, fueron de una magnitud estadística similar ( $>00,1135)$ entre los racimos con y sin desflora. El peso de los frutos exportables de primera calidad, de la calidad mini, así como la cantidad de cajas obtenidas a partir de un racimo para cada calidad o para la suma de ellas fue similar ( $>00,5750)$ entre los racimos con y sin desflora (Cuadro 2). 


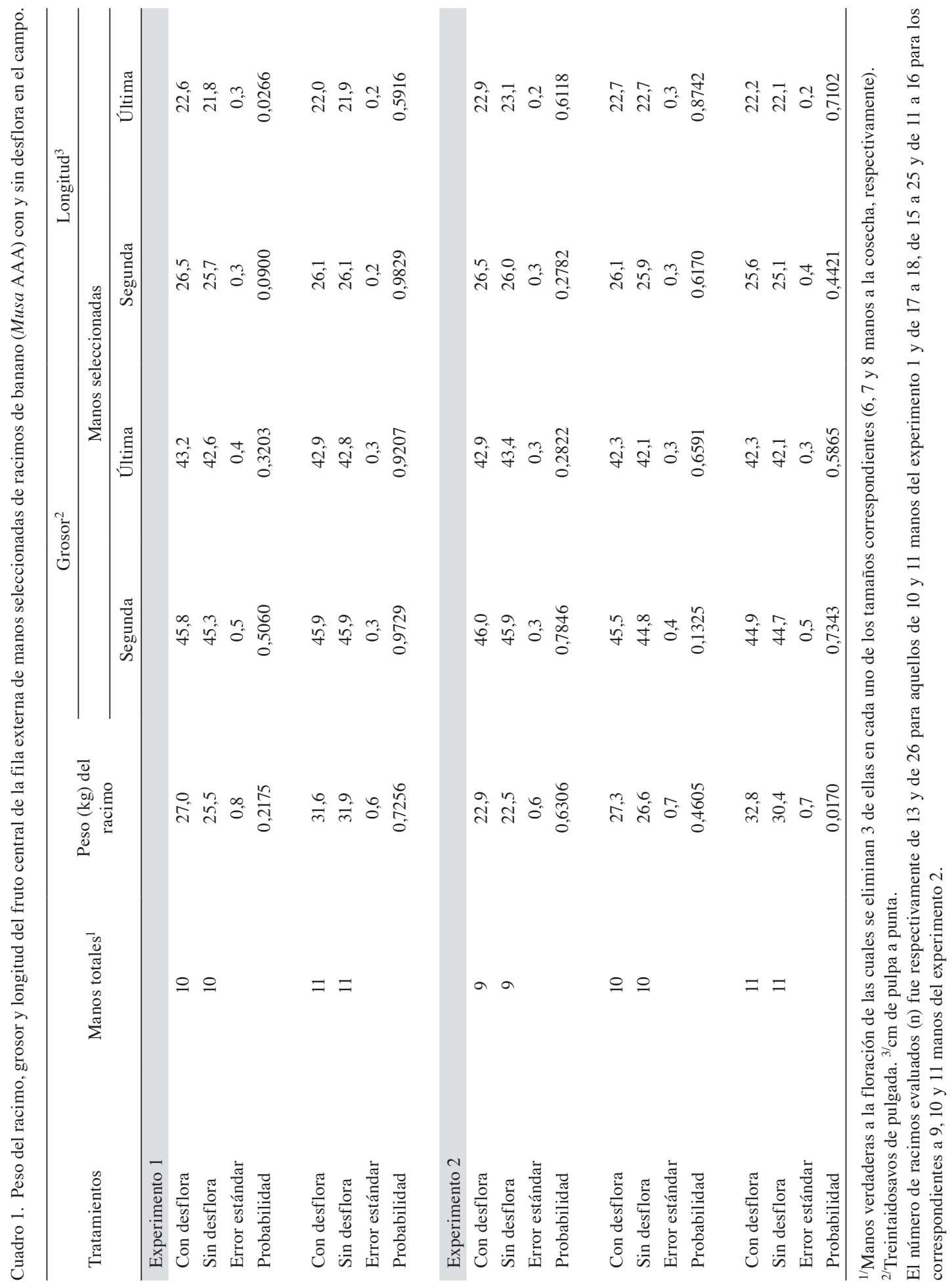


Cuadro 2. Causas de rechazo, merma y aprovechamiento (primera calidad) de racimos de banano (Musa AAA) de 11 (experimento 1) y 10 (experimento 2).

\begin{tabular}{|c|c|c|c|c|c|c|}
\hline & \multicolumn{5}{|c|}{ Tratamientos de desflora } & \\
\hline & \multicolumn{3}{|c|}{ Experimento 1} & \multicolumn{3}{|c|}{ Experimento 2} \\
\hline & Con & $\operatorname{Sin}$ & Prob & Con & Sin & Prob \\
\hline Factores de rechazo & $\%$ & $\%$ & & $\%$ & $\%$ & \\
\hline Deformes & 26,0 & 23,7 & 0,7557 & 36,7 & 43,7 & 0,3726 \\
\hline Lesión nueva & 23,8 & 19,3 & 0,6011 & 20,4 & 16,3 & 0,6111 \\
\hline Cicatriz de crecimiento & 28,4 & 28,7 & 0,9710 & 22,1 & 4,6 & 0,0353 \\
\hline Lesión vieja & 3,2 & 7,1 & 0,4700 & 0,8 & 1,7 & 0,6113 \\
\hline Otros & 18,6 & 21,2 & 0,7048 & 20,1 & 33,7 & 0,1901 \\
\hline Total rechazo (kg) & 3,7 & 4,7 & 0,1135 & 2,8 & 2,9 & 0,9394 \\
\hline $\operatorname{Merma}^{1}(\%)$ & 15,5 & 19,2 & 0,2208 & 11,9 & 11,9 & 0,9919 \\
\hline $\operatorname{Merma}^{2}(\%)$ & 14,0 & 16,9 & 0,1813 & 0 & 0 & - \\
\hline Frutos exportables ${ }^{1}(\mathrm{~kg})$ & 22,6 & 22,3 & 0,7941 & 21,4 & 21,2 & 0,8639 \\
\hline Frutos exportables ${ }^{2}(\mathrm{~kg})$ & 0,4 & 0,6 & 0,5750 & 0 & 0 & - \\
\hline Total exportable & 23,0 & 22,9 & 0,9271 & 21,4 & 21,2 & 0,8639 \\
\hline Ratio $^{1}$ & 1,19 & 1,17 & 0,7982 & 1,13 & 1,12 & 0,8707 \\
\hline Ratio $^{2}$ & 0,02 & 0,03 & 0,5973 & 0 & 0 & - \\
\hline Total & 1,21 & 1,21 & 0,9280 & 1,13 & 1,12 & 0,8707 \\
\hline
\end{tabular}

${ }^{1 /}$ Excluye la calidad 'mini' o 'junior. ${ }^{2 /}$ Solo calidad 'mini' o 'junior.

Manos verdaderas a la floración con y sin desflora en el campo. El número de racimos evaluados por tratamiento fue de 11 para cada experimento.

\section{Experimentos 3 y 4: desgaje}

No hubo diferencias $(\mathrm{p}>0,0620)$ en ninguna de las variables de producción (Cuadro 3) entre racimos con y sin desgaje, excepto por el mayor peso en racimos de 10 manos con desgaje del experimento 3 (1,5 kg más; $\mathrm{p}=0,0051)$ y de 11 manos también con desgaje del experimento 4 (2,0 kg cm más; p=0,0150). El porcentaje de racimos que no alcanzaron el grosor de cosecha exigido para la segunda mano y se cosecharon en etapas posteriores fue respectivamente en los racimos sin (testigo) y con gajo, de 25,8 y $23,8 \%$ en el experimento 1 y de 20,1 y 20,5 en el experimento 2 .

Las causas de rechazo así como la merma (Cuadro 4) fueron estadísticamente similares ( $>00,0652$ ) entre los racimos sin (testigo) y con desgaje. En los experimentos 3 a y 4 el peso de los frutos exportables de primera calidad provenientes tanto de manos completas como del gajo así como de sus similares de calidad mini y la suma de ambas calidades no difirió ( $p>0,3539)$ entre racimos sin y con desgaje, con excepción del peso adicional en la calidad mini proveniente del gajo $(0,3 \mathrm{~kg}$ más; $\mathrm{p}=0,0370)$ del experimento 4. En el experimento $3 \mathrm{~b}$ los racimos con desgaje presentaron un mayor peso de frutos de primera calidad tanto de manos completas (2,5 kg más; $\mathrm{p}=0,0045)$ como total exportable según el aporte del gajo (3,1 kg más; $\mathrm{p}=0,0003)$. La cantidad de cajas por racimo de las manos enteras y el gajo (ratio) entre racimos sin y con desgaje (Cuadro 4) no difirió ( $p>0,3294$ ) tanto para la primera calidad, la calidad mini o la suma de ambas en el experimento 3a. Asimismo en dicho experimento los racimos con desgaje presentaron mayor ratio $(0,17$ más; $\mathrm{p}<0,0007)$, diferencia que se mantuvo $(\mathrm{p}=0,0004)$ en el total 
Cuadro 3. Variables de producción de racimos de banano (Musa AAA) sin y con la conformación de un gajo en la última mano a eliminar por el desmane.

\begin{tabular}{|c|c|c|c|c|c|c|c|c|}
\hline \multirow{3}{*}{ Tratamiento } & \multirow{3}{*}{$\begin{array}{l}\text { Manos } \\
\text { totales }^{1}\end{array}$} & \multirow{3}{*}{$\begin{array}{l}\text { Peso }(\mathrm{kg}) \\
\text { del racimo }\end{array}$} & \multicolumn{4}{|c|}{ Grosor $^{2}$} & \multirow{2}{*}{\multicolumn{2}{|c|}{$\operatorname{Largo}^{3}$}} \\
\hline & & & \multicolumn{4}{|c|}{ Manos seleccionadas } & & \\
\hline & & & $2^{\mathrm{da}}$ & UMC & Gajo & $2^{\mathrm{da}}$ & UMC & Gajo \\
\hline \multicolumn{9}{|l|}{ Experimento 3} \\
\hline Sin gajo & 9 & 21,3 & 44,5 & 42,0 & - & 25,6 & 22,1 & - \\
\hline Con gajo & 9 y gajo & 22,4 & 44,7 & 41,8 & 40,8 & 25,9 & 22,1 & 21,1 \\
\hline Error estándar & & 0,6 & 0,2 & 0,2 & - & 0,3 & 0,2 & - \\
\hline Probabilidad & & 0,1804 & 0,5454 & 0,5896 & - & 0,4025 & 0,8192 & - \\
\hline Sin gajo & 10 & 25,5 & 44,6 & 41,3 & - & 25,6 & 21,4 & - \\
\hline Con gajo & 10 y gajo & 27,0 & 44,5 & 41,7 & 40,8 & 25,6 & 21,8 & 20,7 \\
\hline Error estándar & & 0,4 & 0,2 & 0,2 & - & 0,2 & 0,1 & - \\
\hline Probabilidad & & 0,0051 & 0,8992 & 0,0620 & - & 0,8361 & 0,0662 & - \\
\hline Sin gajo & 11 & 31,3 & 44,3 & 41,3 & - & 25,7 & 21,6 & - \\
\hline Con gajo & 11 y gajo & 30,8 & 44,5 & 40,9 & 39,9 & 25,6 & 21,6 & 20,3 \\
\hline Error estándar & & 0,6 & 0,2 & 0,3 & - & 0,2 & 0,2 & - \\
\hline Probabilidad & & 0,6092 & 0,6332 & 0,1876 & - & 0,6401 & 0,9487 & - \\
\hline \multicolumn{9}{|l|}{ Experimento 4} \\
\hline Sin gajo & 9 & 21,4 & 45,0 & 42,9 & - & 25,2 & 22,2 & - \\
\hline Con gajo & 9 y gajo & 21,7 & 44,8 & 42,7 & 42,3 & 25,1 & 22,2 & 21,2 \\
\hline Error estándar & & 0,8 & 0,3 & 0,4 & - & 0,2 & 0,2 & - \\
\hline Probabilidad & & 0,8429 & 0,6717 & 0,7743 & - & 0,7899 & 0,7691 & - \\
\hline Sin gajo & 10 & 25,1 & 45,2 & 42,7 & - & 25,5 & 21,8 & - \\
\hline Con gajo & 10 y gajo & 25,1 & 44,7 & 42,4 & 41,9 & 25,1 & 21,7 & 21,2 \\
\hline Error estándar & & 0,6 & 0,3 & 0,2 & - & 0,3 & 0,2 & - \\
\hline Probabilidad & & 0,9721 & 0,2077 & 0,4543 & - & 0,3189 & 0,6995 & - \\
\hline Sin gajo & 11 & 27,8 & 44,3 & 42,2 & - & 25,1 & 21,5 & - \\
\hline Con gajo & 11 y gajo & 29,8 & 44,3 & 42,3 & 41,2 & 25,3 & 21,7 & 20,7 \\
\hline Error estándar & & 0,6 & 0,3 & 0,3 & - & 0,2 & 0,1 & - \\
\hline Probabilidad & & 0,0150 & 0,9739 & 0,6392 & - & 0,3679 & 0,3382 & - \\
\hline
\end{tabular}

${ }^{1 /}$ Manos verdaderas a la floración de las cuales se eliminan 3 de ellas en cada uno de los tamaños correspondientes $(6,7$ y 8 manos a la cosecha, respectivamente).

${ }^{2 /}$ Treintaidosavos de pulgada.

${ }^{3 /} \mathrm{cm}$ de pulpa a punta UMC: Última mano comparable.

El número de racimos evaluados (n) fue respectivamente de 19 a 22, de 40 a 51 y de 21 a 29 para aquellos de 9,10 y 11 manos del experimento 3 y, de 13 a 14, de 19 a 24 y de 24 a 26 para los correspondientes a los racimos de 9,10 y 11 manos del experimento 4 . 


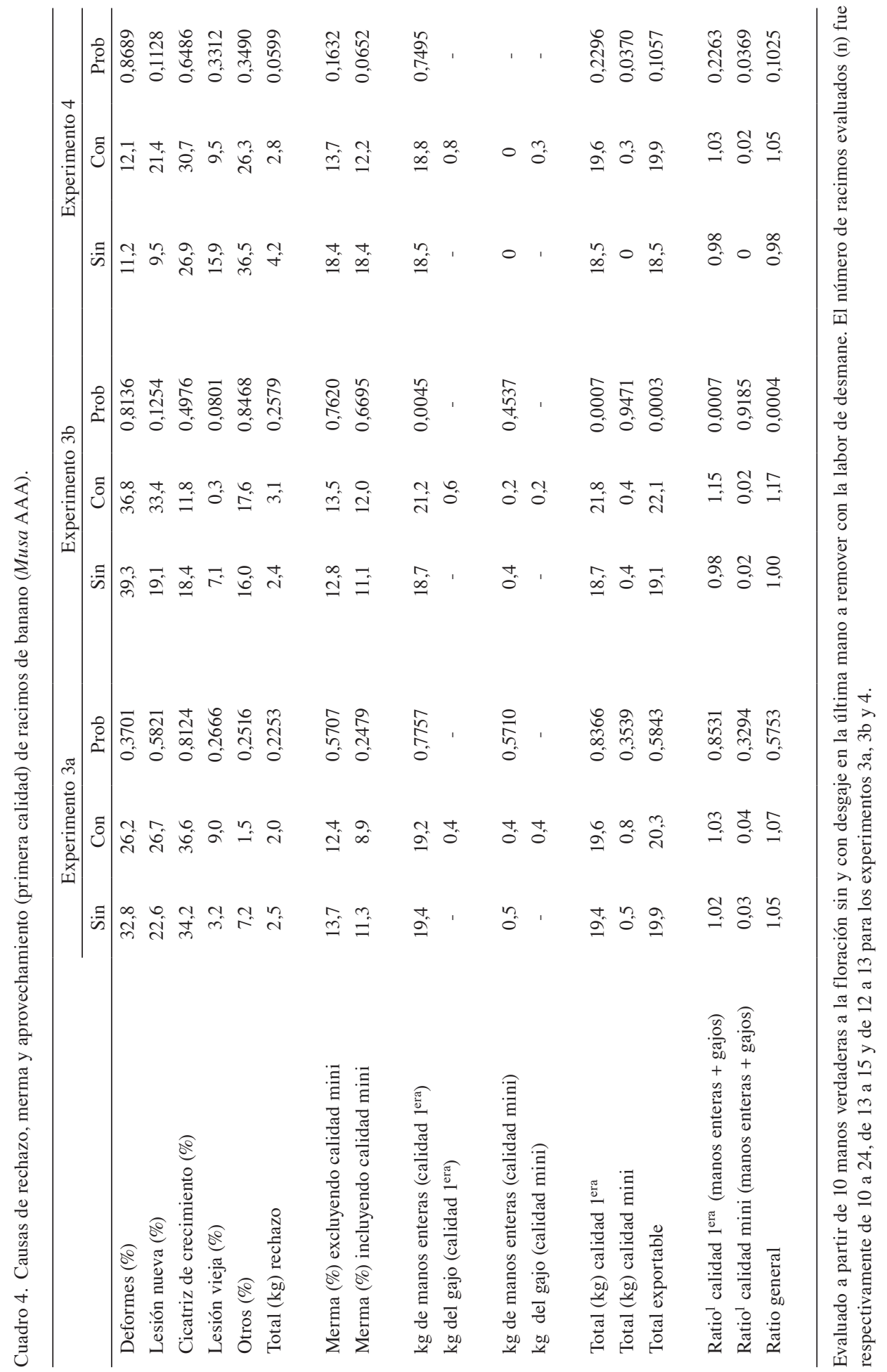


que consideró adicionalmente la calidad mini. En el experimento 4 solo hubo diferencias estadísticas entre tratamientos $(\mathrm{p}<0,0369)$ para la calidad mini que presentaban manos completas y gajo, no obstante, a pesar de que la diferencia de ratio entre tratamientos para la primera calidad (manos completas y gajo) no alcanzó a ser significativa ( $>0,1025)$ éste representó un aumento importante y de consideración económica en los racimos con desgaje (0,07 más).

\section{Experimentos 5 y 6: manejo diferencial de la primera mano y desgaje}

El peso del racimo varió entre tratamientos $(\mathrm{p}<0,0450)$ para ambos experimentos, el mayor valor se presentó con túnel y desgaje y el menor en el que consideró la eliminación de la primera mano. El grosor del fruto central, con excepción de los correspondientes a la primera y cuarta mano del experimento $5(\mathrm{p}=0,0088$ y $\mathrm{p}=0,0109 ;$ respectivamente), no difirió $(\mathrm{p}>0,1044)$ entre tratamientos para ambos experimentos (Cuadro 5). La longitud del fruto central, con excepción del correspondiente a la segunda mano del experimento 5 $(\mathrm{p}=0,0443)$ no difirió $(\mathrm{p}>0,0804)$ entre tratamientos en ambos experimentos (Cuadro 6). En aquellos casos en que las diferencias se expresaron, los mejores valores tanto en grosor como en longitud estuvieron relacionados con los racimos con túnel y gajo.

Cuadro 5. Peso del racimo y grosor del fruto central de la fila externa de manos seleccionadas de racimos (10 manos verdaderas a la floración) de banano (Musa AAA) con diferentes modalidades de manejo.

\begin{tabular}{|c|c|c|c|c|c|c|}
\hline \multirow[t]{2}{*}{ Tratamientos $^{1}$} & \multirow[t]{2}{*}{$\begin{array}{l}\text { Peso del } \\
\text { racimo }\end{array}$} & \multicolumn{5}{|c|}{$\begin{array}{l}\text { Grosor (treintaidosavos de pulgada) } \\
\text { Posición de la mano en el racimo }\end{array}$} \\
\hline & & Primera & Segunda & Cuarta & Sexta & Octava \\
\hline \multicolumn{7}{|c|}{ Experimento 5} \\
\hline 1 & $30,3 b$ & $43,6 a b$ & 44,2 & $42,7 b$ & 42,0 & ----- \\
\hline 2 & $29,2 b$ & $42,9 b$ & 43,7 & $42,6 b$ & 41,8 & ----- \\
\hline 3 & $28,8 b$ & ----- & 44,3 & $44,1 \mathrm{a}$ & 42,8 & 41,8 \\
\hline 4 & $32,3 \mathrm{a}$ & $44,4 \mathrm{a}$ & 44,6 & $43,3 b$ & 42,2 & 41,6 \\
\hline Error estándar & 0,7 & 0,3 & 0,4 & 0,3 & 0,3 & 0,4 \\
\hline Probabilidad & 0,0051 & 0,0088 & 0,3683 & 0,0109 & 0,3460 & 0,8245 \\
\hline \multicolumn{7}{|c|}{ Experimento 6} \\
\hline 1 & $30,5 \mathrm{ab}$ & 43,9 & 44,8 & 43,5 & 42,4 & ----- \\
\hline 2 & $28,9 \mathrm{~b}$ & ----- & 44,9 & 43,8 & 42,6 & 41,3 \\
\hline 3 & $31,3 \mathrm{a}$ & 43,5 & 44,6 & 43,1 & 41,8 & 40,9 \\
\hline Error estándar & 0,7 & 0,3 & 0,3 & 0,3 & 0,3 & 0,3 \\
\hline Probabilidad & 0,0450 & 0,3657 & 0,7060 & 0,3059 & 0,1044 & 0,3103 \\
\hline
\end{tabular}

\footnotetext{
${ }^{1 /}$ Experimento 5: 1= remoción de 3 manos verdaderas apicales. 2= remoción de 2 frutos centrales de cada fila de la primera mano basal (túnel) y de 3 manos verdaderas apicales. 3= remoción de la primera mano basal y de 2 manos verdaderas apicales. $4=$ remoción de 2 frutos centrales de cada fila de la primera mano basal (túnel) gajo en la tercer mano apical y remoción de las 2 manos verdaderas apicales siguientes. Experimento 6: 1= remoción de 3 manos verdaderas apicales. 3= remoción de la primera mano basal y de 2 manos verdaderas apicales. 4 = remoción de 3 frutos centrales de cada fila de la primera mano basal (túnel) gajo en la tercer mano apical y remoción de las 2 manos verdaderas apicales siguientes.

El número de racimos evaluados (n) fue de 18, 1912 y 17 para los tratamientos del 1 al 4 del experimento 5 y de 23,24 y 20 para los tratamientos del 1 al 3 del experimento 6 .
} 
Cuadro 6. Longitud del fruto central de la fila externa de manos seleccionadas de racimos (10 manos verdaderas a la floración) de banano (Musa AAA) con diferentes modalidades de manejo.

\begin{tabular}{|c|c|c|c|c|c|}
\hline \multirow[b]{2}{*}{ Tratamientos $^{1}$} & \multicolumn{5}{|c|}{$\begin{array}{l}\text { Longitud (cm de pulpa a punta) de manos seleccionadas } \\
\text { Posición de la mano en el racimo }\end{array}$} \\
\hline & Primera & Segunda & Cuarta & Sexta & Octava \\
\hline \multicolumn{6}{|c|}{ Experimento 5} \\
\hline 1 & 26,1 & $25,9 \mathrm{a}$ & 24,8 & 23,1 & ---- \\
\hline 2 & 25,5 & $25,3 b$ & 24,6 & 23,2 & ----- \\
\hline 3 & ---- & $25,9 \mathrm{ab}$ & 25,4 & 23,8 & 21,8 \\
\hline 4 & 26,1 & $26,2 \mathrm{a}$ & 24,8 & 23,2 & 21,6 \\
\hline Error estándar & 0,2 & 0,2 & 0,2 & 0,2 & 0,2 \\
\hline Probabilidad & 0,1265 & 0,0443 & 0,0804 & 0,3397 & 0,5544 \\
\hline \multicolumn{6}{|c|}{ Experimento 6} \\
\hline 1 & 24,6 & 24,9 & 23,7 & 22,3 & ---- \\
\hline 2 & ---- & 25,5 & 24,2 & 22,6 & 21,0 \\
\hline 3 & 24,6 & 25,0 & 24,0 & 22,4 & 20,9 \\
\hline Error estándar & 0,2 & 0,2 & 0,2 & 0,2 & 0,2 \\
\hline Probabilidad & 0,9922 & 0,1379 & 0,1372 & 0,5835 & 0,5417 \\
\hline
\end{tabular}

${ }^{1 /}$ Experimento 5: 1= remoción de 3 manos verdaderas apicales. 2= remoción de 2 frutos centrales de cada fila de la primera mano basal (túnel) y de 3 manos verdaderas apicales. $3=$ remoción de la primera mano basal y de 2 manos verdaderas apicales. 4 = remoción de 2 frutos centrales de cada fila de la primera mano basal (túnel) gajo en la tercer mano apical y remoción de las 2 manos verdaderas apicales siguientes. Experimento 6: 1= remoción de 3 manos verdaderas apicales. 3= remoción de la primera mano basal y de 2 manos verdaderas apicales. 4 = remoción de 3 frutos centrales de cada fila de la primera mano basal (túnel) gajo en la tercer mano apical y remoción de las 2 manos verdaderas apicales siguientes.

El número de racimos evaluados (n) fue de 18, 1912 y 17 para los tratamientos del 1 al 4 del experimento 5 y de 23,24 y 20 para los tratamientos del 1 al 3 del experimento 6 .

Los componentes del rechazo, excepto por el mayor porcentaje de lesión nueva $(\mathrm{p}=0,0192)$ en el tratamiento con túnel y gajo no difirieron ( $p>0,2388)$ entre tratamientos para ambos experimentos (Cuadro 7).

El peso de los frutos exportables de primera calidad provenientes de manos completas (se excluye el peso exportable de la primera mano y del gajo) presentó diferencias $(\mathrm{p}=0,0143)$ entre tratamientos en el experimento 5 con el mayor valor en el tratamiento donde se eliminó la primera mano (Cuadro 8). Sin embargo, cuando se adicionaron los pesos exportables correspondientes a la primera mano y al gajo no se encontraron diferencias $(p=0,1981)$ entre tratamientos. Tampoco hubo diferencias entre tratamientos en el peso de la merma de las manos enteras, de la primera mano, del gajo y del total de éstos ( $>00,1108)$ así como para el porcentaje de merma $(p>0,3263)$ y el ratio $(\mathrm{p}=0,1965)$. En el experimento 6, excepto por el mayor valor de la última mano completa $(\mathrm{p}=0,0001)$ en relación con una de su misma posición conformada en gajo (mano 8 en ambos casos) no hubo diferencias entre tratamientos para el peso de las manos enteras, de la primera mano y del total exportable $(\mathrm{p}>0,1132)$ así como para el peso de la merma de las manos enteras, de la primera mano, de la octava mano (completa o gajo), el total de las mismas $(\mathrm{p}<0,0612)$ el porcentaje de merma $(\mathrm{p}=0,1660)$ y el ratio $(\mathrm{p}=0,1143)$. 
Cuadro 7. Causas de rechazo (\%) de frutos de banano (Musa AAA) bajo diferentes modalidades de manejo del racimo.

\begin{tabular}{|c|c|c|c|c|c|}
\hline & \multicolumn{5}{|c|}{ Tratamientos $^{1}$} \\
\hline Factores de merma (\%) & 1 & 2 & 3 & 4 & Prob $^{2}$ \\
\hline \multicolumn{6}{|c|}{ Experimento 5} \\
\hline Deformes & 37,8 & 37,5 & 27,7 & 27,6 & 0,2388 \\
\hline Lesión nueva & 37,6 & 40,8 & 46,5 & 48,4 & 0,4473 \\
\hline Lesión vieja & 3,9 & 1,5 & 9,3 & 8,6 & 0,3634 \\
\hline Cicatriz de crecimiento & 15,1 & 8,6 & 13,9 & 10,7 & 0,7328 \\
\hline Otros & 5,6 & 11,6 & 2,6 & 3,7 & 0,2704 \\
\hline \multicolumn{6}{|c|}{ Experimento 6} \\
\hline & & & 2 & 3 & Prob $^{2}$ \\
\hline Deformes & & & 23,2 & 20,7 & 0,5103 \\
\hline Lesión nueva & & & $29,2 \mathrm{ab}$ & $41,9 \mathrm{a}$ & 0,0192 \\
\hline Lesión vieja & & & 5,4 & 1,1 & 0,4450 \\
\hline Cicatriz de crecimiento & & & 15,1 & 7,7 & 0,3465 \\
\hline Mancha de madurez & & & 22,0 & 19,5 & 0,8445 \\
\hline Otros & & & 5,0 & 9,1 & 0,3538 \\
\hline
\end{tabular}

${ }^{1 /}$ Experimento 5: 1= remoción de 3 manos verdaderas apicales. 2 = remoción de 2 frutos centrales de cada fila de la primera mano basal (túnel) y de 3 manos verdaderas apicales. $3=$ remoción de la primera mano basal y de 2 manos verdaderas apicales. $4=$ remoción de 2 frutos centrales de cada fila de la primera mano basal (túnel) gajo en la tercer mano apical y remoción de las 2 manos verdaderas apicales siguientes. Experimento 6: 1= remoción de 3 manos verdaderas apicales. 2= remoción de la primera mano basal y de 2 manos verdaderas apicales. 3 = remoción de 3 frutos centrales de cada fila de la primera mano basal (túnel) gajo en la tercer mano apical y remoción de las 2 manos verdaderas apicales siguientes.

${ }^{2 /}$ Probabilidad.

El número de racimos evaluados (n) fue de $12,12,9$ y 12 para los tratamientos del 1 al 4 del experimento 5 y de 18 , 18 y 13 para los tratamientos del 1 al 3 del experimento 6. Racimos de 10 manos verdaderas a la floración en ambos casos. 


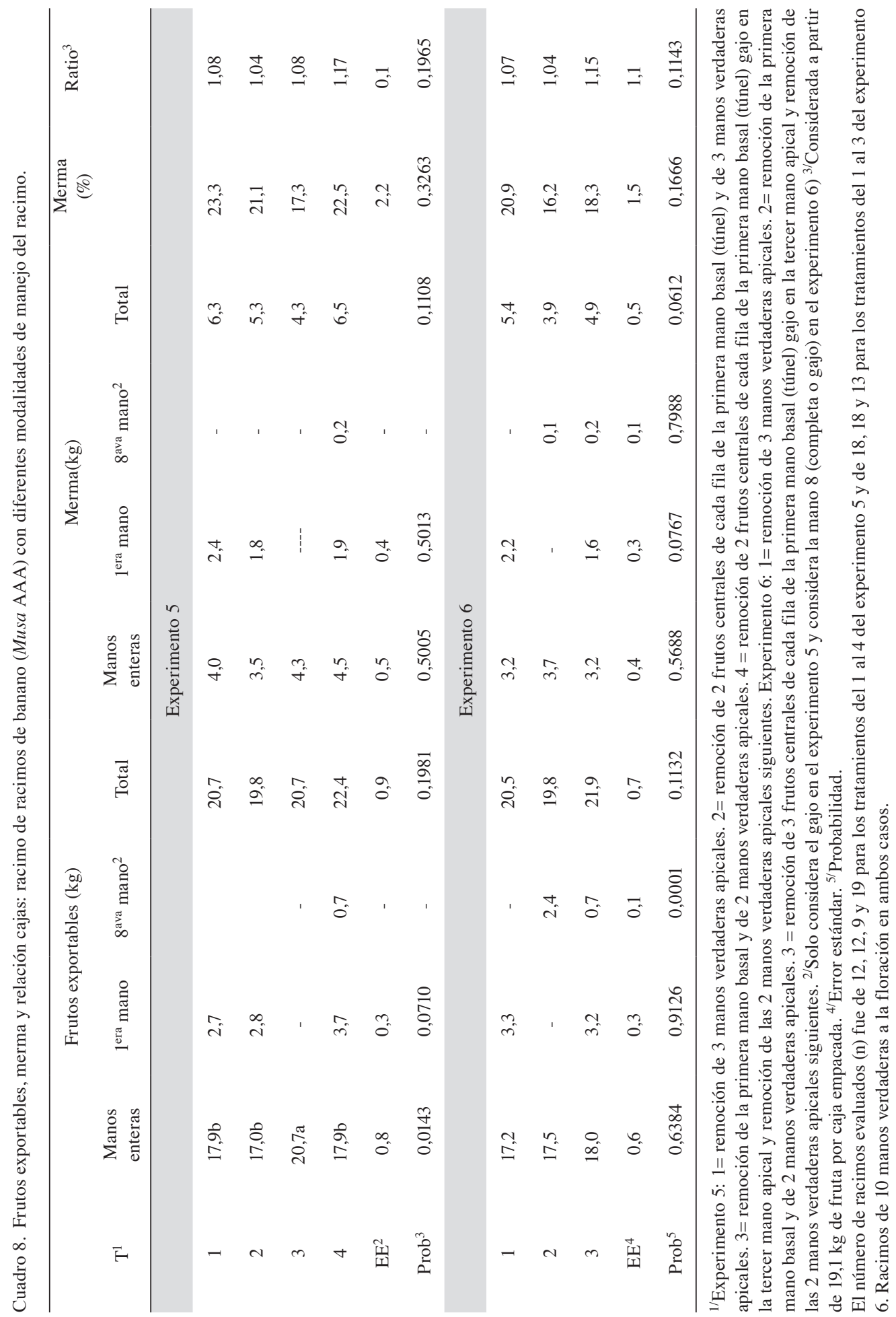




\section{DISCUSIÓN}

\section{Experimentos 1 y 2: desflora}

El similar comportamiento productivo de los frutos entre racimos con y sin desflora en el campo corrobora los resultados obtenidos por Vargas et ál. (2003) quienes indican que esta práctica no provoca un mejoramiento del peso del racimo, de las dimensiones de sus frutos ni del aprovechamiento (ratio) del racimo. Asimismo, la reducción en la cicatriz de crecimiento, aspecto que se determinó en el experimento 2 cuando no se efectuó la labor, es quizá uno de los resultados más relevantes, aspecto también concordante con los resultados obtenidos por Vargas et ál. (2003) y con Rivas et ál. (2009). La alteración en la magnitud de este factor de merma en virtud de una práctica determinada (desflora en este caso) es quizá uno de los pocos componentes de rechazo que son influenciados por una manipulación externa del racimo, componentes que de manera general, aún con la cicatriz de crecimiento, responden básicamente en función de épocas climáticas favorables o adversas, particularidad ya señalada por Vargas (2001, 2002, 2003).

Datos no publicados generados por la finca Zent en el 2005 indican que existe una reducción en el costo de mano de obra cuando no se desflora en el campo de alrededor de $27,2 \%$ y un aumento en los materiales dado básicamente por el costo de la funda con bifentrina cercano al 1,3\%.

$\mathrm{Al}$ respecto, la decisión de no desflorar en el campo debe considerar estrategias de manejo diferenciadas en función de la presencia de insectos en aquellas áreas o épocas donde estos se manifiesten. Esto involucra (Vargas et ál. 2003, Guillen y Laprade 2011, Araya et ál. 2011) el uso de fundas impregnadas con el insecticida bifentrina para el combate del gusano basurero (Pyroderces rileyi), rotación con fundas impregnadas con el insecticida clorpirifos, colocación de cintas de polietileno (corbatas) impregnadas también con clorpirifos, eliminación de vainas secas en el pseudotallo (desburille) y las eventuales aplicaciones de detergentes, aceites o insecticidas al pseudotallo de la planta para el combate de cochinillas (Pseudococcus elisae) y escamas (Diaspis boiduvalii) insectos plaga que de acuerdo con diversos autores (Corporación Bananera Nacional 2004, Corporación Bananera Nacional 2005, Cubillo y Laprade 2006, Cubillo y Laprade 2008) no son controladas eficientemente por la bifentrina pero si por el clorpirifos (Villalobos 2011).

\section{Experimentos 3 y 4: desgaje}

La retención de un grupo de frutos centrales realizada en la mano de mayor posición en el racimo que sería eliminada por el desmane, permitió, de acuerdo con las normas de calidad definidas para la finca donde se efectuó el experimento, un aprovechamiento del gajo sin detrimento de las dimensiones de los frutos remanentes, ni del intervalo de tiempo entre el desmane y la cosecha. Esto es congruente con los resultados de Vargas (2009) en fincas de la zona Este y Oeste del Caribe de Costa Rica. No obstante, la mayor importancia de este conjunto de respuestas está constituida por la posibilidad de definir sin riesgo y de forma práctica y rápida las intensidades de desmane más apropiadas de acuerdo con las condiciones agronómicas y de comercialización de una plantación, particularidad ya mencionada también por Vargas (2009).

Dentro de las causas de rechazo el similar porcentaje correspondiente a deformidades en el fruto entre los racimos sin y con desgaje es un claro indicativo más de que la retención del gajo no compromete la conformación del racimo. Asimismo, cabe mencionar que aunque el porcentaje de daño ocasionado durante la cosecha y el transporte a la planta empacadora (lesión nueva) entre racimos sin y con gajo, a pesar de que no alcanzó a ser estadísticamente diferente, tuvo una magnitud mayor en los racimos con el gajo, situación que podría obedecer a una menor protección al realizar la cosecha entre el gajo y la mano que lo antecede. También es importante notar los altos porcentajes de rechazo ocasionados por cicatriz de crecimiento tanto en los racimos sin y como con gajo, condición que ocurre generalmente 
cuando los racimos, como en este caso, se desfloraron en el campo.

El peso adicional de los frutos del gajo al racimo no fue por lo general de una magnitud que provocara diferencias estadísticas con respecto a un racimo del mismo tamaño sin el gajo. Sin embargo, su aporte como peso neto comercial representó un componente adicional más de rendimiento. Esta consideración es vinculante también en relación con el aporte extra del gajo sobre la cantidad de cajas obtenidas por racimo o 'ratio' para las diferentes calidades empacadas, donde salvo por algunas excepciones, las diferencias entre racimos con y sin el gajo no alcanzaron a ser significativas estadísticamente.

\section{Experimentos 5 y 6: manejo diferencial de la primera mano y desgaje}

La disminución en el peso del racimo conforme la intensidad de remoción de partes aumentó, es congruente con lo indicado por Vargas (2006). En concordancia con lo anterior, la menor reducción estuvo dada en el experimento 1 cuando se removieron 2 manos verdaderas inferiores, se confeccionó el túnel en la primera mano superior y se retuvo un gajo en la mano inferior de mayor posición a descartar por el desmane (tratamiento 4). Esta fue seguida por la remoción de 3 manos verdaderas inferiores (tratamiento 1) y por la remoción de 3 manos verdaderas inferiores y la confección del túnel en la primera mano superior (tratamiento 2). Finalmente, la remoción total de la primera mano superior y la compensación en el desmane mediante la remoción de 2 manos verdaderas inferiores (tratamiento 3) fue donde se observó la mayor pérdida de peso. De igual manera esto sucedió en su orden en el experimento 2 para los tratamientos 3, 1 y 2 . Asimismo no hubo un efecto diferencial de las diferentes modalidades de manejo del racimo sobre las medidas de grosor y longitud del fruto por lo que no hubo una compensación sobre los frutos remanentes en el racimo en función de la intensidad de remoción de partes del mismo.

No fue posible en la mayoría de los casos determinar diferencias estadísticas entre tratamientos para los diferentes factores de rechazo. No obstante la expresión de deformidades siempre fue mayor cuando no se efectuó ninguna medida de mitigación en la primera mano como en el tratamiento 1 y se redujo por lo general en aquellos tratamientos donde las medidas consistieron en la eliminación de la primera mano o en la confección del túnel en dicha mano y la retención de un gajo de mano inferior. Dado que en esta finca (Encantos del Mar Rojo) el problema de deformidad en la primera mano es un problema importante este resultado sugiere que en el contexto antes citado, ambas alternativas de mitigación podrían considerarse como válidas. Asimismo, de nuevo la lesión ocasionada durante la cosecha y el transporte a la planta empacadora (lesión nueva) presenta porcentajes muy altos, diferencia que sí alcanzó a ser significativa en el experimento 6 con un mayor porcentaje en el tratamiento donde se retuvo el gajo, situación que en este caso, podría obedecer en parte a una menor protección a la hora de la cosecha entre el gajo y la mano que lo antecede, pero sobre todo a un manejo poco apropiado del racimo cosechado.

La diferencia en el rendimiento exportable que solamente se declaró en el experimento 1 para el peso de las manos enteras y a favor del tratamiento con eliminación de la primera mano, debe ser analizado cuidadosamente ya que en el procedimiento estadístico el análisis del peso, las manos enteras y de la primera mano se efectuó por aparte para cada uno de sus valores. Por esto, la cantidad de manos que incluyó el tratamiento con eliminación de la primera mano fue de 7 y de 6 para los restantes. Una vez considerado lo anterior en función del peso total exportable es claro que tanto éste como la cantidad de cajas obtenidas a partir de un racimo presentan un mejor comportamiento a partir de aquellos racimos donde se retuvo la primera mano y se confeccionaron el túnel y el gajo.

La reducción de la merma del peso en ambos experimentos, en la primera mano que se logró con la conformación del túnel respecto al tratamiento sin dicha labor (tratamientos 1 y 2 del experimento 5 y tratamientos 1 y 3 del 
experimento 3), indica que la práctica de remover grupos de frutos centrales en ambas filas de la primera mano podría ser considerada como parte de las estrategias de manejo del racimo cuando existen problemas por un exceso de frutos que puedan inducir deformidad. Esto cobra mayor importancia conforme aumenta la incidencia de frutos fusionados o guapes, así como el número de frutos totales en dicha mano, condición que ocasionaría en virtud de su magnitud como respuesta, una distribución irregular y desordenada de los mismos. Ante esta perspectiva es necesario determinar la o las intensidades de remoción óptimas de frutos centrales para las 3 primeras manos del racimo, a partir de la variación estacional del número de frutos totales y de frutos fusionados de estas manos.

De acuerdo con los resultados obtenidos así como lo indicado por Vargas (2006) las manos superiores constituyen la porción más importante del racimo para el empaque; la remoción total de la primera mano probablemente solo puede justificarse en aquellos casos en que esta se presente como una mano 'mica' con mucho menos frutos esto es 14 o menos de lo normal ya sea por situaciones o condiciones especiales de manejo propias de la finca que no permitan medidas de mitigación.

\section{LITERATURA CITADA}

ARAYA H., BOLAÑOS D., GAMBOA F., SOJO J., BOLANOS E. 2011. Precosecha, pp. 13-34. In: E. Bolaños (ed.). Manual de Buenas Prácticas Agrícolas en el Cultivo del Banano. Dirección de Asistencia Técnica, CORBANA S.A. San José, Costa Rica.

CALVO J. 1984. Efecto del desmane en la calidad del fruto del banano (Musa AAA, Sub grupo Cavendish 'Gran enano'). Tesis de licenciatura, Universidad de Costa Rica, San José, Costa Rica. 55 p.

CHAMPION J. 1975. El plátano. Editorial Blume. 247 p.

CORPORACIÓN BANANERA NACIONAL. 2004. Evaluación de fundas de polietileno impregnadas con diferentes sustancias (clorpirifos, clorpirifos + azufre, bifentrina y, chile + ajo) y una funda de polipropileno $\left(\operatorname{Agriban}^{\circledR}\right)$ para la protección del racimo de banano, pp. 64-66. In: A. Vargas y R. Vargas (eds.). Informe Anual 2003. Dirección de Investigaciones. Corporación Bananera Nacional. Guápiles, Costa Rica.
CORPORACIÓN BANANERA NACIONAL. 2005. Evaluación del control de plagas insectiles en racimos de banano (Musa AAA, cv. Grande Naine) con fundas impregnadas con bifentrina, pp. 113-114. In: J. Sandoval y S. Laprade (eds.). Informe anual 2004. Dirección de Investigaciones. Corporación Bananera Nacional. Guápiles, Costa Rica.

COTO D., SAUNDERS J.L. 2004. Insectos plagas de cultivos perennes con énfasis en frutales en América Central. Turrialba, Costa Rica. CATIE. (Serie técnica. Manual técnico / CATIE No. 52). 420 p.

CUBILLO D. 2004. Evaluación de fundas de polietileno impregnadas con diferentes sustancias (clorpirifos, clorpirifos + azufre, bifentrina y chile + ajo) y una funda de polipropileno (Agriban) usadas para la protección del racimo del banano, pp. 64-66. In: A. Vargas y R. Vargas (eds.). Informe Anual 2003. Dirección de Investigaciones. Corporación Bananera Nacional. Guápiles, Costa Rica.

CUBILLO D., LAPRADE S. 2006. Evaluación de fundas con ingredientes naturales incorporados al polietileno para el control de insectos en el cultivo de banano, pp. 151-155. In: J. Sandoval (ed.). Informe Anual 2005. Dirección de Investigaciones. Corporación Bananera Nacional. Guápiles, Costa Rica.

CUBILlO D., LAPRADE S. 2008. Eficacia biológica de fundas impregnadas con mezclas de sustancias naturales en la protección del racimo de banano (Musa AAA) contra insectos plaga, pp. 158-159. In: J. Sandoval (ed.). Informe Anual 2007. Dirección de Investigaciones. Corporación Bananera Nacional. Guápiles, Costa Rica.

CUBillo D., VIllalta R., GUZMÁN M. 2003 Evaluación de fundas de polietileno con insecticidas (clorpirifos, bifentrina y rotenona) y de polipropileno sin insecticida (AGRIBAN ${ }^{\circledR}$ ) para la protección de los racimos de banano contra insectos plagas, pp. 39-40. In: J. Sandoval (ed.). Informe Anual 2002. Dirección de Investigaciones. Corporación Bananera Nacional. Guápiles, Costa Rica.

DAUDIN J. 1953. Epistillage des regimenes de bananes sur pied. Fruits (8)10:488-489.

GUILLÉN C., LAPRADE S. 2011. Programación de embolses en Finca San Pablo, pp. 133-135. In: J. Sandoval (ed.). Informe Anual 2010. Dirección de Investigaciones. Corporación Bananera Nacional. Guápiles, Costa Rica.

RIVAS R., BOLAÑOS E., RAMÍREZ M., PINEDA J. 2009. Beneficios en el uso y aplicación del perfil del racimo, pp. 45. In: J. Sandoval (ed.). Tercer Congreso Científico-Técnico Bananero Nacional. Dirección de Investigaciones. Corporación Bananera Nacional. Guápiles, Costa Rica.

ROBINSON J. 1996. Bananas and Plantains. CAB International. UK. 238 p. 
RODRÍGUEZ J. 1996. Biología del gusano basurero Pyrodercis rileyi en flores de banano (Musa spp. 'Cavendish') en la zona Atlántica de Costa Rica. Tesis de licenciatura. Escuela de Agricultura de la Región Tropical Húmeda. Guácimo, Costa Rica. $30 \mathrm{p}$.

SANDOVAL J., PÉREZ L. 1998. Efecto de combinar las prácticas de desdede y desflora sobre la calidad del fruto de banano cv. 'Gran Enano' (Musa AAA), pp. 24-25. In: R. Vargas y J. Sandoval (eds.). Informe Anual 1997. Dirección de Investigaciones, Corporación Bananera Nacional. Guápiles, Costa Rica.

SANDOVAL J., PÉREZ L., GUZMÁN, M. 2000. Desflora en el campo en el cultivo del banano (Musa AAA, cv. 'Gran Enano'). CORBANA 26(53):01-10.

SAS. 1989. User Guide-Version 6. $4^{\text {th }}$ ed. Volume I. SAS Institute Inc. Cary, NC. 943 p.

SOTO M., SOTO E., SOLÍS P., LÓPEZ A. 1992. Siembra y operaciones de cultivo, pp. 211-363. In: M. Soto. (ed.). Bananos: Cultivo y Comercialización. Segunda Edición. Litografía e imprenta LIL, S.A. San José, Costa Rica.

UQUILLAS C.M. 2002. Caracterización de Pyroderces sp., (Lepidoptera: Cosmopterigidae) en banano de Ecuador, pp. 296-300. In: Asociación de Bananeros de Colombia AUGURA (eds.). XV Reunión Internacional ACORBAT 2002. Memorias. Cartagena de Indias, Colombia.

VARGAS A. 2001. Efecto de la intensidad de desmane sobre el peso del racimo y las dimensiones del fruto de banano (Musa AAA, cvs. Gran Enano y Valery) en dos épocas del año. CORBANA 27(54):13-14.

VARGAS A. 2002. Alta intensidad de desmane en banano (Musa AAA, cvs. Grande Naine y Williams), su efecto sobre el peso del racimo y las dimensiones de los frutos. CORBANA 28(55):27-42.

VARGAS A. 2003. Efecto de tres intensidades de desdede sobre el desarrollo del racimo de banano (Musa
AAA, cvs. Grande Naine y Valery). CORBANA 28(56):27-38.

VARGAS A. 2006. Efecto de la retención de la última mano o de la remoción parcial o total de frutos de la primera mano sobre las características y el rendimiento de racimos de banano (Musa AAA). CORBANA 32(59):1-16.

VARGAS A. 2007. Efecto de la eliminación de frutos laterales de las últimas manos sobre el desarrollo del fruto del banano (Musa AAA, cv. Williams), pp.158159. In: J. Sandoval (ed.). Informe Anual 2006. Dirección de Investigaciones, Corporación Bananera Nacional, Guápiles Costa Rica.

VARGAS A. 2008. Efecto de la combinación de las prácticas de desmane y desgaje sobre el desarrollo del fruto de banano (Musa AAA, cv. Grande Naine), pp. 112-114. In: J. Sandoval (ed.). Informe Anual 2007. Dirección de Investigaciones. Corporación Bananera Nacional, Guápiles, Costa Rica.

VARGAS A. 2009. Efecto de la combinación de las prácticas de desgaje y desmane sobre las dimensiones de los frutos y el rendimiento del racimo de banano (Musa AAA, subgrupo Cavendish). CORBANA 35(62):1-15.

VARGAS A., BLANCO F. 2000. Consideraciones metodológicas para la evaluación del desmane en banano (Musa AAA, cv. 'Valery). InfoMusa 9(2):19-21.

VARGAS A., CUBILLO D., MORA E. 2003. Evaluación de la desflora en el campo y de fundas impregnadas con bifentrina o clorpirifos sobre el desarrollo del racimo de banano (Musa AAA, cv. Grande Naine) y la incidencia de plagas del fruto. CORBANA 26(56):39-52.

VILLALOBOS R.M. 2011. Efecto de las características y composición de las fundas para racimos sobre las variables de producción, la severidad del speckling y la incidencia de otras plagas y daños del fruto de banano (Musa AAA, cv. Grande Naine). Tesis de licenciatura, ITCR. San Carlos, Costa Rica. 102 p. 